\title{
Construction and Restrictions of Consistent Matrices by Macharis' Method
}

\author{
Chun-Hsiao Chu $\mathbb{D},{ }^{1}$ Shu-Cheng Lin, ${ }^{2}$ and Peterson Julian $\mathbb{i D}^{3}$ \\ ${ }^{1}$ Department of Tourism, Aletheia University, No. 32, Zhenli St., Danshui Dist., New Taipei City 25103, Taiwan \\ ${ }^{2}$ Department of Hotel Management, Lee-Ming Institute of Technology, Taiwan \\ ${ }^{3}$ Department of Traffic Science, Central Police University, Taiwan
}

Correspondence should be addressed to Chun-Hsiao Chu; shawchu@mail.au.edu.tw

Received 5 May 2018; Revised 24 September 2018; Accepted 16 October 2018; Published 28 October 2018

Academic Editor: Anna M. Gil-Lafuente

Copyright (c) 2018 Chun-Hsiao Chu et al. This is an open access article distributed under the Creative Commons Attribution License, which permits unrestricted use, distribution, and reproduction in any medium, provided the original work is properly cited.

\begin{abstract}
In 2004, Macharis et al. proposed a consistent comparison matrix. In this study, we provide a patch work for discussing the construction and restrictions of their consistent comparison matrix. Their study is important in academia and has been cited by over 200 papers. However, in the article, the authors neither provide a detailed explanation on how to construct the proposed revised consistent comparison matrix nor mention any restriction when constructing it. In this study, we not only propose an algorithm to construct the consistent matrix, but also prove that two restrictions exist when developing a sequence of their consistent comparison matrices, which are: (a) the changing of entries should follow a decreasing order with respect to the row index and (b) there is at most one entry in each row that can be revised by experts. The results of this study will help researchers properly apply the consistent matrices proposed by Macharis et al. (2004) in the future.
\end{abstract}

\section{Introduction}

To provide reasonable related weights among alternatives (or criteria) is a critical factor during the process of multicriteria decision-making problems. Baek et al. [1] claimed that there are limitations to acquire sufficient information for the selected input parameters of statistical data in the area of life cycle assessment (LCA). Hence, there is a strong requirement for a consistent process to locate the input parameters for use in uncertainty analysis in the field of LCA when only partial information for a comparison matrix is known. Macharis et al. [2] discusses the advantages and shortcomings of the Preference Ranking Organization METHod for Enrichment Evaluations (PROMETHEE) to point out that it did not provide a systematical method to assign weights for the objectives. Hence, Macharis et al. [2] adopted Analytic Hierarchy Process (AHP) methods to incorporate AHP into PROMETHEE and then operational synergies can be obtained in multicriteria analysis. Because of its flexibility and easy implementation, AHP was applied to obtain relative weights for criteria and alternatives in many fields.
At first, we recall the original $\mathrm{n}$ by $\mathrm{n}$ consistent matrix proposed by Macharis et al. [2]. To construct a consistent comparison matrix, Macharis et al. [2] first established the first row as $a_{1, j}$ for $j=1,2, \ldots, n$, and for the rest entries $a_{i, j}=a_{i, 1} / a_{j, 1}$, for $i=2,3, \ldots, n$ and $j=1,2, \ldots, n$.

Second, based on the above construction, Macharis et al. [2] proposed a revised process, which involves developing a consistent comparison matrix and asking an expert to know which entries should be changed. Subsequently, the previous study provided an example and mentioned that a chosen expert wanted to change $\left\{a_{57}, a_{26}, a_{15}, a_{24}\right\}$ and explicitly added that $a_{57}$ should be revised to 2 . However, the preferred values for $\left\{a_{26}, a_{15}, a_{24}\right\}$ was not provided based on the expert opinion. Finally, the previous authors did not change the values of $\left\{a_{26}, a_{15}, a_{24}\right\}$, after having revised the value of $a_{57}$, and instead changed the value of $a_{45}$ from $5 / 2$ to 2 . Therefore, Macharis et al. [2] only demonstrated these two instances of entry changing and did not provide any procedure or algorithm in obtaining the new consistent matrices. There are new methods and progress for consistency, for example, Dong and Herrera-Viedma [3], Dong 
et al. [4], and Li et al. [5]. Dong and Herrera-Viedma [3] constructed a new linear programming model to find interval numerical scale for linguistic term sets which are interval fuzzy preference relations. Dong et al. [4] developed a new consensus process to synthesize heterogeneous alternatives, attributes, and preference relations for complex and dynamic 1 multiple attribute group decision-making problems. Li et al. [5] provided a new framework to personalize individual semantics with hesitant fuzzy linguistic terms sets such that reflected individual personalized difference in understanding the meaning of comparative linguistic expressions in hesitant linguistic group decision-making.

The first goal of this paper is to provide an algorithm to help practitioners obtain a new consistent comparison matrix based on the changing of one predesigned entry. The second goal is to discuss the two restrictions during the revised process to further amend the questionable results in Macharis et al. [2].

Up until now, there have been 233 papers that cited Macharis et al. [2] in their references, which indicates that their paper is a popular research item. We classified those papers into the following four categories:

(i) Authors developed their new multicriteria decisionmaking problems. For example, Alonso et al. [6] tried to solve the missing entries in pairwise preference values under incomplete fuzzy, multiplicative, interval-valued, and linguistic preference relations. Mutikanga et al. [7] applied multicriteria decision analysis as a strategic planning tool for water loss management. Salardini [8] combined AHP and grey relation analysis to arrange portfolio management by trade off risk and reward. Hashemian et al. [9] used a fuzzy hybrid group decision support system to measure the supplier evaluation process. Parajuli et al. [10] adopted multicriteria assessment of yellow, green, and woody biomasses to prescreen available biomass types to provide prepare for a sustainable system. Rahman et al. [11] developed a multicriteria decision analysis approach to decide the best inland waterway structure.

(ii) Other authors dealt with application-oriented problems and did not focus on how the consistent comparison matrix proposed by Macharis et al. [2] was constructed. For example, Ayoko et al. [12] applied multicriteria decision-making methods to enhance air quality in the environment of residential houses in Brisbane, Australia. Soltani and Marandi [13] used AHP and Analytic Network Process (ANP) to set a two-stage fuzzy multicriteria decision-making process of a hospital site selection. Wang et al. [14] adopted an AHP weighted aggregated data quality indicator approach to evaluate embodied energy of building materials. Alexakis and Sarris [15] studied landfill setting in Western, Crete by integrating geographical information systems and remote sensing analysis. Tsui and Wen [16] considered a hybrid multiple criteria group decision-making approach for green supplier selection in the thin film transistor liquid crystal display industry. For a case study on mineral exploration in Varan area, Markazi province, Iran, Feizi et al. [17] applied a concentration-area fractal model. For another case study in Farmahin Area, Markazi Province, Iran, Feizi et al. [18] adopted the Technique for Order of Preference by Similarity to Ideal Solution (TOPSIS) with hybrid AHP-Shannon entropy weighting of evidence.

(iii) Another set of authors focused on other issues related to PROMETHEE. For example, Bilsel et al. [19] studied about Turkish hospitals and constructed performance measures to evaluate their websites with fuzzy and crisp data. Ramzan et al. [20] applied multicriteria decision analysis in a case study to assess safety and the economics of a distillation column unit using PROMETHEE. Fontana and Morais [21] used PROMETHEE $\mathrm{V}$ to weigh alternatives to resolve a water delivery network with detected leaks. Roodposhti et al. [22] considered PROMETHEE II with fuzzy AHP to construct a landslide susceptibility mapping of Minoo Dasht in Iran. Pourghahreman and Qhatari [23] applied TOPSIS and PROMETHEE $\Pi$ to select suppliers in a pharmaceutical supply chain. For national forest parks in Greece, Andreopoulou et al. [24] developed the multicriteria method of PROMETHEE II to derive the total ranking through Internet technologies. Vesyropoulos and Georgiadis [25] integrated AHP with PROMETHEE III to derive a novel approach to measure attractiveness under imprecise assessment environments by a categoricalbased evaluation technique. Wang et al. [26] combined a two-phase PROMETHEE method with AHP to execute a comprehensive evaluation of the alternative reconfiguration schemes.

(iv) Lastly, some authors studied other operational research problems without any discussion of AHP. For example, Salardini [8] developed a new model to select suppliers of motor repair services in Brazil. Ghazilla et al. [27] constructed a decision support model to help the product recovery for disassembly. Hamzeh et al. [28] applied a raster-based outranking method to set a new approach for municipal solid waste landfill. Vinodh et al. [29] used a hybrid multicriteria decision-making approach for agile concept selection with fuzzy decision-making trial and evaluation laboratory, and fuzzy technique for order preference by similarity to ideal solution. Zhang et al. [30] adopted a complete ranking model for multicriteria decision-making problems with multigraded dominance relations.

Those papers only mentioned Macharis et al. [2] in their introduction and did not apply the consistent comparison matrix as proposed. This paper claims that the cited article only demonstrated the construction of two revised consistent comparison matrices but did not present the method on how to construct a revised consistent matrix proposed by their approach. After careful investigation, this paper focuses on the development of an algorithm to generate the matrix 
identical to the two examples proposed by Macharis et al. [2]. This fills the gap that was previously overlooked in deriving a consistent revised comparison matrix. Furthermore, as the original and subsequent studies did not provide an examination for the matrix development, this paper puts forth two restrictions to execute a sequence of changes of entries proposed by experts. The first restriction is related to the order of changing. The previous paper claimed that it must follow a decreasing order via the column index. For example, the expert wanted to modify four entries as $\left\{a_{57}, a_{26}, a_{15}, a_{24}\right\}$ as arranged by the decreasing order of column index. The next section shows that the order of changing entries should still follow a decreasing order but through the row index. Consequently, this results to the first restriction where the order should be $\left\{a_{57}, a_{26}, a_{24}, a_{15}\right\}$ or $\left\{a_{57}, a_{24}, a_{26}, a_{15}\right\}$.

The second restriction is related to the allowable number of entries that can be changed in a single row. This paper suggests that a maximum of one entry can be revised in each row, and following this restriction, the proper order should be $\left\{a_{57}, a_{26}, a_{15}\right\}$ or $\left\{a_{57}, a_{24}, a_{15}\right\}$.

The main purpose of this paper is to offer an algorithm and show that this can obtain the three desired properties proposed by Macharis et al. [2] for the new consistent comparison matrix.

The proposed algorithm has four significant features:

(a) A detailed item-by-item procedure to preserve the three desired properties proposed by Macharis et al. [2].

(b) A verified algorithm to prove this approach will derive a consistent and reciprocal matrix to help researchers incorporate AHP into PROMETHEE.

(c) Execution of the revision of $\left\{a_{57}, a_{26}, a_{15}, a_{24}\right\}$ to identify that the use of descending order via the column index is questionable, and to propose an improvement wherein the descending order should be applied on the row index instead.

(d) A further examination by the suggested two entries on the same row proposed by Macharis et al. [2] reveals that it will result in an endless revision process. Hence, a second restriction is recommended.

Our findings will help researchers realize how to revise an entry of a consistent comparison matrix to develop a new consistent revised comparison matrix proposed by Macharis et al. [2].

The following sections are organized as follows: Section 2 provides a brief review for Macharis et al. [2]; Section 3 discusses the proposed improvement that presents the approach to develop a new matrix, under a predesigned entry and the proof that it is reciprocal, is consistent, and satisfies the three desired properties; Section 4 sets out a numerical example to illustrate the algorithm and also to reveal two questionable assertions in Macharis et al. [2] with the discussion of the two restrictions; and Section 5 presents the main findings and recommendations for further research.

\section{Brief Review for Macharis et al. [2]}

The main shortcoming of AHP is that it needs a large number of pairwise comparisons between alternatives or criteria, which usually results in inconsistency in the comparison matrix. The main goal of Macharis et al. [2] is to reduce the number of pairwise comparison inputs in AHP without compromising consistency. Based on Saaty [31, 32], to construct an $\mathrm{n}$ by $\mathrm{n}$ comparison matrix for $\mathrm{n}$ alternatives needs $n(n-1) / 2$ times pairwise comparison for $\left[a_{i j}\right]_{n \times n}$, with $a_{i i}=1$ for $i=1,2, \ldots, n$. Macharis et al. [2] developed a method to construct a consistent matrix for comparison matrix for criteria that only needs $n-1$ times pairwise comparison.

Macharis et al. [2] then invited an expert to decide entries for $a_{1 i}$ for $i=2,3, \ldots, n$, that is the first row of the comparison matrix, and assumed that

$$
a_{i j}=\frac{a_{1 j}}{a_{1 i}}
$$

For $i=2,3, \ldots, n$, and $j=1,2, \ldots, n$, wherein the expert will then select several entries to modify their values.

Macharis et al. [2] demonstrated the results of their original comparison matrix, denoted as $\left[x_{i j}\right]_{8 \times 8}$, in Table 1 .

Such paper mentioned that the expert wanted to change the values of $\left\{a_{57}, a_{26}, a_{15}, a_{24}\right\}$ as arranged by the descending order via column index.

They further claimed that the expert wanted to change the value of $a_{57}$ from $7 / 5$ to 2 . Table 2 shows the second comparison matrix, denoted as $\left[y_{i j}\right]_{8 \times 8}$.

Macharis et al. [2] pointed out that, in such table, the same entries of $y_{i j}=x_{i j}$, for $1 \leq i, j \leq 5$, and for $6 \leq i, j \leq 8$. Those identical values are marked by bold italic font in Table 2 .

They further claimed that the expert wanted another revision for $a_{45}$ from $5 / 2$ to 2 . The third comparison matrix is cited in Table 3.

Macharis et al. [2] pointed out that, in Table 3 , the same entries of $z_{i j}=y_{i j}$, for $1 \leq i, j \leq 4$, and for $5 \leq i, j \leq 8$. Those identical values are marked by bold font in Table 3 .

However, Macharis et al. [2] did not explain how to develop the new revised comparison matrix after a specific entry is changed. One of the objectives of this paper is to provide a reasonable method to show that how to construct a revised comparison matrix that satisfies the requirements proposed by Macharis et al. [2].

\section{Our Improvement}

The original consistent comparison matrix is denoted as $\left[a_{i j}\right]_{n \times n}$ and a specific entry, denoted as $a_{\alpha \beta}$, with $\alpha<\beta$, is assigned to a new value $\delta$ and the new matrix is denoted as $\left[b_{i j}\right]_{n \times n}$. Based on the bold italic font entries in Table 2 and bold font in Table 3, it is known that the new matrix satisfies three properties:

Property (P1): $b_{i j}=a_{i j}$, for $1 \leq i, j \leq \alpha$;

Property (P2): $b_{i j}=a_{i j}$, for $\alpha+1 \leq i, j \leq n$;

Property (P3): $b_{\alpha \beta}=\delta$.

The new matrix, $\left[b_{i j}\right]_{n \times n}$, is defined by the following four rules:

(1) If $1 \leq i \leq \alpha$ and $1 \leq j \leq \alpha$, then $b_{i j}=a_{i j}$. 
TABLE 1: Reproduction of Table 5 in Macharis et al. [2].

\begin{tabular}{|c|c|c|c|c|c|c|c|c|}
\hline$D$ & $C_{1}$ & $C_{2}$ & $C_{3}$ & $C_{4}$ & $C_{5}$ & $C_{6}$ & $C_{7}$ & $C_{8}$ \\
\hline$C_{1}$ & 1 & 2 & 3 & 2 & 5 & $2 / 3$ & 7 & 3 \\
\hline$C_{2}$ & $1 / 2$ & 1 & $3 / 2$ & 1 & $5 / 2$ & $1 / 3$ & $7 / 2$ & $3 / 2$ \\
\hline$C_{3}$ & $1 / 3$ & $2 / 3$ & 1 & $2 / 3$ & $5 / 3$ & $2 / 9$ & $7 / 3$ & 1 \\
\hline$C_{4}$ & $1 / 2$ & 1 & $3 / 2$ & 1 & $5 / 2$ & $1 / 3$ & $7 / 2$ & $3 / 2$ \\
\hline$C_{5}$ & $1 / 5$ & $2 / 5$ & $3 / 5$ & $2 / 5$ & 1 & $2 / 15$ & $7 / 5$ & $3 / 5$ \\
\hline$C_{6}$ & $3 / 2$ & 3 & $9 / 2$ & 3 & $15 / 2$ & 1 & $21 / 2$ & $9 / 2$ \\
\hline$C_{7}$ & $1 / 7$ & $2 / 7$ & $3 / 7$ & $2 / 7$ & $5 / 7$ & $2 / 21$ & 1 & $3 / 7$ \\
\hline$C_{8}$ & $1 / 3$ & $2 / 3$ & 1 & $2 / 3$ & $5 / 3$ & $2 / 9$ & $7 / 3$ & 1 \\
\hline
\end{tabular}

TABle 2: Reproduction of Table 6 in Macharis et al. [2].

\begin{tabular}{|c|c|c|c|c|c|c|c|c|}
\hline$D$ & $C_{1}$ & $C_{2}$ & $C_{3}$ & $\mathrm{C}_{4}$ & $C_{5}$ & $C_{6}$ & $C_{7}$ & $C_{8}$ \\
\hline$C_{1}$ & 1 & 2 & 3 & 2 & 5 & $20 / 21$ & 10 & $30 / 7$ \\
\hline$C_{2}$ & $1 / 2$ & 1 & $3 / 2$ & 1 & $5 / 2$ & $10 / 21$ & 5 & $15 / 7$ \\
\hline$C_{3}$ & $1 / 3$ & $2 / 3$ & 1 & $2 / 3$ & $5 / 3$ & $20 / 63$ & $10 / 3$ & $10 / 7$ \\
\hline$C_{4}$ & $1 / 2$ & 1 & $3 / 2$ & 1 & $5 / 2$ & $10 / 21$ & 5 & $15 / 7$ \\
\hline$C_{5}$ & $1 / 5$ & $2 / 5$ & $3 / 5$ & $2 / 5$ & 1 & $4 / 21$ & 2 & $6 / 7$ \\
\hline$C_{6}$ & $21 / 20$ & $21 / 10$ & $63 / 20$ & $21 / 10$ & $21 / 4$ & 1 & $21 / 2$ & $9 / 2$ \\
\hline$C_{7}$ & $1 / 10$ & $1 / 5$ & $3 / 10$ & $1 / 5$ & $1 / 2$ & $2 / 21$ & 1 & $3 / 7$ \\
\hline$C_{8}$ & $7 / 30$ & $7 / 15$ & $7 / 10$ & $7 / 15$ & $7 / 6$ & $2 / 9$ & $7 / 3$ & 1 \\
\hline
\end{tabular}

(2) If $1 \leq i \leq \alpha$ and $\alpha+1 \leq j \leq n$, then $b_{i j}=a_{i \alpha} \delta a_{\beta j}$.

(3) If $\alpha+1 \leq i \leq n$ and $1 \leq j \leq \alpha$, then $b_{i j}=a_{i \beta}(1 / \delta) a_{\alpha j}$.

(4) If $\alpha+1 \leq i \leq n$ and $\alpha+1 \leq j \leq n$, then $b_{i j}=a_{i j}$. The proposed algorithm decomposes the matrix construction process into manageable steps. From this construction, we know that Properties (P1) and (P2) are satisfied. The following section illustrates the proof that the proposed new matrix is reciprocal, that is, $b_{i j} b_{j i}=1$, and consistent, that is, $b_{i j} b_{j k}=b_{i k}$, and then satisfies Property (P3) $b_{\alpha \beta}=\delta$.

\section{Theorem 1. The proposed matrix is reciprocal.}

Proof. The proof is divided into four cases: Case $1,1 \leq i \leq \alpha$ and $1 \leq j \leq \alpha$, Case $2,1 \leq i \leq \alpha$ and $\alpha+1 \leq j \leq n$, Case 3 , $\alpha+1 \leq i \leq n$ and $1 \leq j \leq \alpha$, and Case $4, \alpha+1 \leq i \leq n$ and $\alpha+1 \leq j \leq n$.

For Case 1, the following is presented:

$$
b_{i j} b_{j i}=a_{i j} a_{j i}=1
$$

since the original comparison matrix, $\left[a_{i j}\right]_{n \times n}$ is reciprocal.

For Case 2, it is derived that

$$
b_{i j} b_{j i}=a_{i \alpha} \delta a_{\beta j} a_{j \beta}\left(\frac{1}{\delta}\right) a_{\alpha i}=a_{i \alpha} a_{\alpha i} a_{j \beta} a_{\beta j}=a_{i i} a_{j j}=1 .
$$

For Case 3, it is computed that

$$
b_{i j} b_{j i}=a_{i \beta}\left(\frac{1}{\delta}\right) a_{\alpha j} a_{j \alpha} \delta a_{\beta i}=a_{j \alpha} a_{\alpha j} a_{i \beta} a_{\beta i}=a_{j j} a_{i i}=1 .
$$

For Case 4, it is evaluated as

$$
b_{i j} b_{j i}=a_{i j} a_{j i}=1 \text {. }
$$

For all four cases, $b_{i j}=1 / b_{j i}$, for $1 \leq i, j \leq n$ proving that the developed matrix is reciprocal.
Theorem 2. The proposed matrix is consistent.

Proof. Eight cases are presented to support the proof: Case $\mathrm{A}, 1 \leq i \leq \alpha, 1 \leq j \leq \alpha$ and $1 \leq k \leq \alpha$; Case $\mathrm{B}, 1 \leq i \leq \alpha$, $\alpha+1 \leq j \leq n$ and $1 \leq k \leq \alpha$; Case C, $\alpha+1 \leq i \leq n, 1 \leq j \leq \alpha$ and $1 \leq k \leq \alpha$; Case D, $\alpha+1 \leq i \leq n, \alpha+1 \leq j \leq n$ and $1 \leq k \leq \alpha$; Case E, $1 \leq i \leq \alpha, 1 \leq j \leq \alpha$ and $\alpha+1 \leq k \leq n$; Case F, $1 \leq i \leq \alpha, \alpha+1 \leq j \leq n$ and $\alpha+1 \leq k \leq n$; Case $\mathrm{G}, \alpha+1 \leq i \leq n, 1 \leq j \leq \alpha$ and $\alpha+1 \leq k \leq n$; Case $\mathrm{H}$, $\alpha+1 \leq i \leq n, \alpha+1 \leq j \leq n$ and $\alpha+1 \leq k \leq n$.

For Case A,

$$
b_{i j} b_{j k}=a_{i j} a_{j k}=a_{i k}=b_{i k} .
$$

For Case B,

$$
b_{i j} b_{j k}=a_{i \alpha} \delta a_{\beta j} a_{j \beta}\left(\frac{1}{\delta}\right) a_{\alpha k}=a_{i k}=b_{i k} .
$$

For Case C,

$$
b_{i j} b_{j k}=a_{i \beta}\left(\frac{1}{\delta}\right) a_{\alpha j} a_{j k}=a_{i \beta}\left(\frac{1}{\delta}\right) a_{\alpha k}=b_{i k} .
$$

For Case D,

$$
b_{i j} b_{j k}=a_{i j} a_{j \beta}\left(\frac{1}{\delta}\right) a_{\alpha k}=a_{i \beta}\left(\frac{1}{\delta}\right) a_{\alpha k}=b_{i k} .
$$

For Case E,

$$
b_{i j} b_{j k}=a_{i j} a_{j \beta}\left(\frac{1}{\delta}\right) a_{\alpha k}=a_{i \beta}\left(\frac{1}{\delta}\right) a_{\alpha k}=b_{i k} .
$$

For Case F,

$$
b_{i j} b_{j k}=a_{i \alpha} \delta a_{\beta j} a_{j k}=a_{i \alpha} \delta a_{\beta k}=b_{i k} .
$$


TABLE 3: Reproduction of Table 7 in Macharis et al. [2].

\begin{tabular}{|c|c|c|c|c|c|c|c|c|}
\hline$D$ & $C_{1}$ & $C_{2}$ & $C_{3}$ & $C_{4}$ & $C_{5}$ & $C_{6}$ & $C_{7}$ & $C_{8}$ \\
\hline$C_{1}$ & 1 & 2 & 3 & 2 & 4 & $21 / 16$ & 8 & $24 / 7$ \\
\hline$C_{2}$ & $1 / 2$ & 1 & $3 / 2$ & 1 & 2 & $8 / 21$ & 4 & $12 / 7$ \\
\hline$C_{3}$ & $1 / 3$ & $2 / 3$ & 1 & $2 / 3$ & $4 / 3$ & $16 / 63$ & $8 / 3$ & $8 / 7$ \\
\hline$C_{4}$ & $1 / 2$ & 1 & $3 / 2$ & 1 & 2 & $8 / 21$ & 4 & $12 / 7$ \\
\hline$C_{5}$ & $1 / 4$ & $1 / 2$ & $3 / 4$ & $1 / 2$ & 1 & $4 / 21$ & 2 & $6 / 7$ \\
\hline$C_{6}$ & $21 / 16$ & $21 / 8$ & $63 / 16$ & $21 / 8$ & $21 / 4$ & 1 & $21 / 2$ & $9 / 2$ \\
\hline$C_{7}$ & $1 / 8$ & $1 / 4$ & $3 / 8$ & $1 / 4$ & $1 / 2$ & $2 / 21$ & 1 & $3 / 7$ \\
\hline$C_{8}$ & $7 / 24$ & $7 / 12$ & $7 / 8$ & $7 / 12$ & $7 / 6$ & $2 / 9$ & $7 / 3$ & 1 \\
\hline
\end{tabular}

For Case G,

$$
b_{i j} b_{j k}=a_{i \beta}\left(\frac{1}{\delta}\right) a_{\alpha j} a_{j \alpha} \delta a_{\beta k}=a_{i \beta} a_{\beta k}=a_{i k}=b_{i k} .
$$

For Case $\mathrm{H}$,

$$
b_{i j} b_{j k}=a_{i j} a_{j k}=a_{i k}=b_{i k} .
$$

For all eight cases, $b_{i j} b_{j k}=b_{i k}$, for $1 \leq i, j, k \leq n$ proving that the developed matrix is consistent.

Theorem 3. The proposed comparison matrix satisfies $b_{\alpha \beta}=\delta$.

Proof. Since $\alpha+1 \leq \beta \leq n$, it is found that

$$
b_{\alpha \beta}=a_{\alpha \alpha} \delta a_{\beta \beta}=\delta \text {. }
$$

Theorems 1, 2, and 3 show that the developed matrix not only satisfies the previously proposed three desired properties but also is reciprocal and consistent.

\section{Numerical Examples}

The effectiveness of the proposed rules is tested using two numerical examples proposed by Macharis et al. [2].

To help readers and practitioners, the computer program used in this study can be accessed at http://bit.ly/2s $4 \mathrm{~h} 3 \mathrm{bC}$ such that interested parties can apply this to adjust selected entries item by item to satisfy revisions provided by experts.

For completeness, this paper provides an algorithm to help interested readers in developing their own computer program.

\section{Algorithm}

Step 1. The original consistent comparison matrix is expressed as $\left[c_{i j}\right]_{m \times m}$.

Step 2. The expert decides to change an entry, denoted as $c_{s t}$, with $s<t$ and a specific value, say $\Delta$.

Step 3. The new consistent comparison matrix will be expressed as $\left[d_{i j}\right]_{m \times m}$, after the following four steps.

Step 4. For $1 \leq i \leq s$ and $1 \leq j \leq s$, then $d_{i j}=c_{i j}$,
Step 5. For $1 \leq i \leq s$ and $s+1 \leq j \leq m$, then $d_{i j}=c_{i s} \Delta c_{t j}$,

Step 6. For $s+1 \leq i \leq m$ and $1 \leq j \leq s$, then $d_{i j}=c_{i t}(1 / \Delta) c_{s j}$,

Step 7. For $s+1 \leq i \leq m$ and $s+1 \leq j \leq m$, then $d_{i j}=c_{i j}$.

Step 8. End.

For the two examples proposed by Macharis et al. [2], changing the entry $(5,7)$ from $7 / 5$ to 2 in the first example and $(4,5)$ from $5 / 2$ to 2 in the second example will yield the same results as Tables 2 and 3. Hence, there is no apparent need to list the findings again. Interested readers can apply the program using the link mentioned above. Instead, this section concentrates on the two questionable results in Macharis et al. [2] during the revised process.

Let us recall that Macharis et al. [2] mentioned that the expert wanted to change the values of $\left\{a_{57}, a_{26}, a_{15}, a_{24}\right\}$ that was arranged by the descending order of column index. Then, the expert wanted to alter $a_{57}$ from $7 / 5$ to 2 . However, there was no setting of predesigned values for $\left\{a_{24}, a_{15}, a_{26}\right\}$. Thus, this paper assumes that the desired values for $\left\{a_{24}, a_{15}, a_{26}\right\}$ are $\{1 / 2,6,2\}$. Applying the proposed algorithm produces the results as shown in Tables $4-6$.

Table 7 exhibits the differences for $\left\{a_{57}, a_{26}, a_{15}, a_{24}\right\}$ in Tables 1, 2, 4, 5, and 6 .

Table 7 shows that based on the changing order previously proposed, the satisfaction rate is up to $75 \%$ for the first three changes. However, the percentage drops to $50 \%$ on the fourth change. The preferred entry $(2,6)$ and entry $(1,5)$ are lost after the modification of entry $(2,4)$. Therefore, the next criterion is provided to decide the order for changing.

The first criterion: the order of changes should be arranged by the descending order of row index.

After our criterion, the order of change should be arranged by the descending order of row index. Reconsidering the same set $\left\{a_{57}, a_{26}, a_{24}, a_{15}\right\}$ and the previous discussions, it is assumed that the expert wanted to change (a) $a_{26}$ from $10 / 21$ to $1 / 2$ and (b) $a_{24}$ from 1 (in Table 2, and $21 / 20$ in Table 8 ) to 2 . To clearly distinguish our results, they are denoted as $\left[e_{i j}\right]_{8 \times 8}$ and $\left[f_{i j}\right]_{8 \times 8}$. The algorithm was applied twice and the results of such are presented in Tables 8 and 9.

Table 9 shows that the value of $f_{26}$ does not satisfy the desired result $1 / 2$. Hence, this paper executed the algorithm the third time to change $f_{26}$ to $1 / 2$, and list the findings in Table 10, denoted as $\left[g_{i j}\right]_{8 \times 8}$. 
TABLE 4: Changing entry $(2,6)$ from $10 / 21$ to $1 / 2$ for the matrix in Table 2.

\begin{tabular}{ccccccccc}
\hline$D$ & $C_{1}$ & $C_{2}$ & $C_{3}$ & $C_{4}$ & $C_{5}$ & $C_{6}$ & $C_{7}$ \\
\hline$C_{1}$ & 1 & 2 & $63 / 20$ & $21 / 10$ & $21 / 4$ & 1 & $21 / 2$ & $9 / 2$ \\
\hline$C_{2}$ & $1 / 2$ & 1 & $63 / 40$ & $21 / 20$ & $21 / 8$ & $1 / 2$ & $21 / 4$ \\
\hline$C_{3}$ & $20 / 63$ & $40 / 63$ & 1 & $2 / 3$ & $5 / 3$ & $20 / 63$ & $10 / 3$ & $10 / 7$ \\
\hline$C_{4}$ & $10 / 21$ & $20 / 21$ & $3 / 2$ & 1 & $5 / 2$ & $10 / 21$ & 5 & $15 / 7$ \\
\hline$C_{5}$ & $4 / 21$ & $8 / 21$ & $3 / 5$ & $2 / 5$ & 1 & 21 & $6 / 7$ \\
\hline$C_{6}$ & 1 & 2 & $63 / 20$ & $21 / 10$ & $21 / 4$ & 1 & $21 / 2$ \\
\hline$C_{7}$ & $2 / 21$ & $4 / 21$ & $3 / 10$ & $1 / 5$ & $1 / 2$ & $2 / 21$ & 1 \\
\hline$C_{8}$ & $2 / 9$ & $4 / 9$ & $7 / 10$ & $7 / 15$ & $7 / 6$ & $2 / 9$ & $7 / 3$ \\
\hline
\end{tabular}

TABLE 5: Changing entry $(1,5)$ from 21/4 to 6 for the matrix in Table 4.

\begin{tabular}{|c|c|c|c|c|c|c|c|c|}
\hline$D$ & $C_{1}$ & $C_{2}$ & $\mathrm{C}_{3}$ & $\mathrm{C}_{4}$ & $C_{5}$ & $C_{6}$ & $C_{7}$ & $C_{8}$ \\
\hline$C_{1}$ & 1 & $16 / 7$ & $18 / 5$ & $12 / 5$ & 6 & $8 / 7$ & 12 & $36 / 7$ \\
\hline$\overline{C_{2}}$ & $7 / 16$ & 1 & $63 / 40$ & $21 / 20$ & $21 / 8$ & $1 / 2$ & $21 / 4$ & $9 / 4$ \\
\hline$C_{3}$ & $5 / 18$ & $40 / 63$ & 1 & $2 / 3$ & $5 / 3$ & $20 / 63$ & $10 / 3$ & $10 / 7$ \\
\hline $\mathrm{C}_{4}$ & $5 / 12$ & $20 / 21$ & $3 / 2$ & 1 & $5 / 2$ & $10 / 21$ & 5 & $15 / 7$ \\
\hline$\overline{C_{5}}$ & $1 / 6$ & $8 / 21$ & $3 / 5$ & $2 / 5$ & 1 & $4 / 21$ & 2 & $6 / 7$ \\
\hline $\mathrm{C}_{6}$ & $7 / 8$ & 2 & $63 / 20$ & $21 / 10$ & $21 / 4$ & 1 & $21 / 2$ & $9 / 2$ \\
\hline$C_{7}$ & $1 / 12$ & $4 / 21$ & $3 / 10$ & $1 / 5$ & $1 / 2$ & $2 / 21$ & 1 & $3 / 7$ \\
\hline$C_{8}$ & $7 / 36$ & $4 / 9$ & $7 / 10$ & $7 / 15$ & $7 / 6$ & $2 / 9$ & $7 / 3$ & 1 \\
\hline
\end{tabular}

TABLE 6: Changing entry $(2,4)$ from $21 / 20$ to 2 for the matrix in Table 5.

\begin{tabular}{lcccccccc}
\hline$D$ & $C_{1}$ & $C_{2}$ & $C_{3}$ & $C_{4}$ & $C_{5}$ & $C_{6}$ & $C_{7}$ \\
\hline$C_{1}$ & 1 & $16 / 7$ & $48 / 7$ & $32 / 7$ & $80 / 7$ & $320 / 147$ & $160 / 7$ & $480 / 49$ \\
\hline$C_{2}$ & $7 / 16$ & 1 & 3 & 2 & 5 & $20 / 21$ & $30 / 7$ \\
\hline$C_{3}$ & $7 / 48$ & $1 / 3$ & 1 & $2 / 3$ & $5 / 3$ & $20 / 63$ & 10 & $10 / 3$ \\
\hline$C_{4}$ & $7 / 32$ & $1 / 2$ & $3 / 2$ & 1 & $5 / 2$ & $10 / 21$ & 5 & $15 / 7$ \\
\hline$C_{5}$ & $7 / 80$ & $1 / 5$ & $3 / 5$ & $2 / 5$ & 1 & $4 / 21$ & 2 \\
\hline$C_{6}$ & $147 / 320$ & $21 / 20$ & $63 / 20$ & $21 / 10$ & $21 / 4$ & 1 & $21 / 2$ \\
\hline$C_{7}$ & $7 / 160$ & $1 / 10$ & $3 / 10$ & $1 / 5$ & $1 / 2$ & $2 / 21$ & 1 & $9 / 2$ \\
\hline$C_{8}$ & $49 / 480$ & $7 / 30$ & $7 / 10$ & $7 / 15$ & $7 / 6$ & $2 / 9$ & & $7 / 3$ \\
\hline
\end{tabular}

TABLE 7: Varies for $\left\{a_{57}, a_{26}, a_{15}, a_{24}\right\}$.

\begin{tabular}{lccccc}
\hline & Table 1 & Table 2 & Table 4 & Table 5 & Table 6 \\
\hline entry $(5,7)$ & $7 / 5$ & 2 & 2 & 2 & $1 / 2$ \\
\hline entry $(2,6)$ & $1 / 3$ & $10 / 21$ & $1 / 2$ & 6 & $20 / 21$ \\
\hline entry $(1,5)$ & 5 & 5 & $21 / 4$ & $80 / 7$ \\
\hline entry $(2,4)$ & 1 & 1 & $21 / 20$ & $21 / 20$ & 2 \\
\hline Satisfaction rate & $0 \%$ & $25 \%$ & $50 \%$ & $75 \%$ & $50 \%$ \\
\hline
\end{tabular}

TABLE 8: Changing entry $(2,6)$ from $10 / 21$ to $1 / 2$ for the matrix in Table 2.

\begin{tabular}{ccccccccc}
\hline$D$ & $C_{1}$ & $C_{2}$ & $C_{3}$ & $C_{4}$ & $C_{5}$ & $C_{6}$ & $C_{7}$ \\
\hline$C_{1}$ & 1 & 2 & $63 / 20$ & $21 / 10$ & $21 / 4$ & 1 & $21 / 2$ & $9 / 2$ \\
\hline$C_{2}$ & $1 / 2$ & 1 & $63 / 40$ & $21 / 20$ & $21 / 8$ & $1 / 2$ & $21 / 4$ \\
\hline$C_{3}$ & $20 / 63$ & $40 / 63$ & 1 & $2 / 3$ & $5 / 3$ & $20 / 63$ & $10 / 3$ & $10 / 7$ \\
\hline$C_{4}$ & $10 / 21$ & $20 / 21$ & $3 / 2$ & 1 & $5 / 2$ & $10 / 21$ & 5 & $15 / 7$ \\
\hline$C_{5}$ & $4 / 21$ & $8 / 21$ & $3 / 5$ & $2 / 5$ & 1 & $4 / 21$ & 1 & $21 / 2$ \\
\hline$C_{6}$ & 1 & 2 & $63 / 20$ & $21 / 10$ & $21 / 4$ & $1 / 2$ & $9 / 2$ \\
\hline$C_{7}$ & $2 / 21$ & $4 / 21$ & $3 / 10$ & $1 / 5$ & $7 / 2$ & 1 \\
\hline$C_{8}$ & $2 / 9$ & $4 / 9$ & $7 / 10$ & $7 / 15$ & $7 / 6$ & $2 / 9$ & $7 / 3$ \\
\hline
\end{tabular}


TABLE 9: Changing entry $(2,4)$ from $21 / 20$ to 2 for the matrix in Table 8 .

\begin{tabular}{|c|c|c|c|c|c|c|c|c|}
\hline$D$ & $C_{1}$ & $C_{2}$ & $C_{3}$ & $\mathrm{C}_{4}$ & $C_{5}$ & $C_{6}$ & $C_{7}$ & $C_{8}$ \\
\hline$C_{1}$ & 1 & 2 & 6 & 4 & 10 & $40 / 21$ & 20 & $60 / 7$ \\
\hline$C_{2}$ & $1 / 2$ & 1 & 3 & 2 & 5 & $20 / 21$ & 10 & $30 / 7$ \\
\hline$C_{3}$ & $1 / 6$ & $1 / 3$ & 1 & $2 / 3$ & $5 / 3$ & $20 / 63$ & $10 / 3$ & $10 / 7$ \\
\hline$C_{4}$ & $1 / 4$ & $1 / 2$ & $3 / 2$ & 1 & $5 / 2$ & $10 / 21$ & 5 & $15 / 7$ \\
\hline$C_{5}$ & $1 / 10$ & $1 / 5$ & $3 / 5$ & $2 / 5$ & 1 & $4 / 21$ & 2 & $6 / 7$ \\
\hline$C_{6}$ & $21 / 40$ & $21 / 20$ & $63 / 20$ & $21 / 10$ & $21 / 4$ & 1 & $21 / 2$ & $9 / 2$ \\
\hline$C_{7}$ & $1 / 20$ & $1 / 10$ & $3 / 10$ & $1 / 5$ & $1 / 2$ & $2 / 21$ & 1 & $3 / 7$ \\
\hline$C_{8}$ & $7 / 60$ & $7 / 30$ & $7 / 10$ & $7 / 15$ & $7 / 6$ & $2 / 9$ & $7 / 3$ & 1 \\
\hline
\end{tabular}

TABLE 10: Changing $f_{26}$ from $20 / 21$ to $1 / 2$ for the matrix in Table 9.

\begin{tabular}{lcccccccc}
\hline$D$ & $C_{1}$ & $C_{2}$ & $C_{3}$ & $C_{4}$ & $C_{5}$ & $C_{6}$ & $C_{7}$ \\
\hline$C_{1}$ & 1 & 2 & $63 / 20$ & $21 / 10$ & $21 / 4$ & 1 & $21 / 2$ & $9 / 2$ \\
\hline$C_{2}$ & $1 / 2$ & 1 & $63 / 40$ & $21 / 20$ & $21 / 8$ & $1 / 2$ & $21 / 4$ \\
\hline$C_{3}$ & $20 / 63$ & $40 / 63$ & 1 & $2 / 3$ & $5 / 3$ & $20 / 63$ & $10 / 3$ & $10 / 7$ \\
\hline$C_{4}$ & $10 / 21$ & $20 / 21$ & $3 / 2$ & 1 & $5 / 2$ & $10 / 21$ & 5 & $15 / 7$ \\
\hline$C_{5}$ & $4 / 21$ & $8 / 21$ & $3 / 5$ & $2 / 5$ & 1 & $4 / 21$ & 1 & $21 / 2$ \\
\hline$C_{6}$ & 1 & 2 & $63 / 20$ & $21 / 10$ & $21 / 4$ & $1 / 2$ & $2 / 21$ & 1 \\
\hline$C_{7}$ & $2 / 21$ & $4 / 21$ & $3 / 10$ & $1 / 5$ & $7 / 9$ & $3 / 7$ \\
\hline$C_{8}$ & $2 / 9$ & $4 / 9$ & $7 / 10$ & $7 / 15$ & $7 / 6$ & $2 / 9$ & $7 / 3$ \\
\hline
\end{tabular}

TABLE 11: Changing $g_{24}$ from 21/20 to 2 for the matrix in Table 10.

\begin{tabular}{|c|c|c|c|c|c|c|c|c|}
\hline$D$ & $C_{1}$ & $C_{2}$ & $C_{3}$ & $C_{4}$ & $C_{5}$ & $C_{6}$ & $C_{7}$ & $C_{8}$ \\
\hline$C_{1}$ & 1 & 2 & 6 & 4 & 10 & $40 / 21$ & 20 & $60 / 7$ \\
\hline$C_{2}$ & $1 / 2$ & 1 & 3 & 2 & 5 & $20 / 21$ & 10 & $30 / 7$ \\
\hline$C_{3}$ & $1 / 6$ & $1 / 3$ & 1 & $2 / 3$ & $5 / 3$ & $20 / 63$ & $10 / 3$ & $10 / 7$ \\
\hline$C_{4}$ & $1 / 4$ & $1 / 2$ & $3 / 2$ & 1 & $5 / 2$ & $10 / 21$ & 5 & $15 / 7$ \\
\hline$C_{5}$ & $1 / 10$ & $1 / 5$ & $3 / 5$ & $2 / 5$ & 1 & $4 / 21$ & 2 & $6 / 7$ \\
\hline $\mathrm{C}_{6}$ & $21 / 40$ & $21 / 20$ & $63 / 20$ & $21 / 10$ & $21 / 4$ & 1 & $21 / 2$ & $9 / 2$ \\
\hline$C_{7}$ & $1 / 20$ & $1 / 10$ & $3 / 10$ & $1 / 5$ & $1 / 2$ & $2 / 21$ & 1 & $3 / 7$ \\
\hline$C_{8}$ & $7 / 60$ & $7 / 30$ & $7 / 10$ & $7 / 15$ & $7 / 6$ & $2 / 9$ & $7 / 3$ & 1 \\
\hline
\end{tabular}

Table 10 provides that $g_{26}=1 / 2$ but $g_{24}=21 / 20 \neq 2$. A fourth execution is done to change $g_{24}$ from $21 / 20$ to 2 , and results are listed in Table 11, denoted as $\left[h_{i j}\right]_{8 \times 8}$.

After comparing the findings in Tables $8-11$, it is revealed that $\left[e_{i j}\right]_{8 \times 8}=\left[g_{i j}\right]_{8 \times 8}$ and $\left[f_{i j}\right]_{8 \times 8}=\left[h_{i j}\right]_{8 \times 8}$. It is possible to claim the revision process to generate two sequences denotes as $\left[a_{i j}^{(n)}\right]_{8 \times 8}$, where $n$ indicates the $n$th revision. Owing to

$$
\left[a_{i j}^{(1)}\right]_{8 \times 8}=\left[e_{i j}\right]_{8 \times 8}=\left[g_{i j}\right]_{8 \times 8}=\left[a_{i j}^{(3)}\right]_{8 \times 8}
$$

and

$$
\left[a_{i j}^{(2)}\right]_{8 \times 8}=\left[f_{i j}\right]_{8 \times 8}=\left[h_{i j}\right]_{8 \times 8}=\left[a_{i j}^{(4)}\right]_{8 \times 8},
$$

we know that $\left[a_{i j}^{(2 k+1)}\right]_{8 \times 8}=\left[e_{i j}\right]_{8 \times 8}$ for $k=1,2, \ldots$, and $\left[a_{i j}^{(2 k)}\right]_{8 \times 8}=\left[f_{i j}\right]_{8 \times 8}$ for $k=1,2, \ldots$ to imply an endless revision process such that the revision of two entries in the same row as in Macharis et al. [2] is questionable. A summary of results is given in the next criterion.
The second criterion: when the expert decides to select several entries to modify their values one by one, there must only be a maximum of one entry per row that can be modified.

Based on criterion 2, the expert should decide whether he/she wishes to change (a) $\left\{a_{57}, a_{26}, a_{15}\right\}$ or (b) $\left\{a_{57}, a_{24}, a_{15}\right\}$.

The consistency approach proposed by Macharis et al. [2] will help researchers improve the consistency index for their comparison matrices to guarantee every decision maker having a consistent comparison matrix during the aggregation process, before the consensus reaching process starts to be iterated.

There are new methods and progress for consensus process, for example, Dong et al. [33], Li et al. [34], and Li et al. [35]. Dong et al. [33] developed a self-management mechanism for noncooperative behaviors in large-scale group consensus reaching processes to decrease the evaluation values of experts with noncooperative behaviors. Li et al. [34] constructed a consensus procedure that preserves the consistency 
index for decision makers. They found an approximated adjustment interval for the optimal adjustment interval and then they verified that after several iterations to improve the group consensus level, then the group consensus level can pass the predesigned consensus level. Li et al. [35] studied a new consensus method to convert an expert from an unacceptable group to an acceptable group with the help of a selected moderator. Each time, one decision maker joins the acceptable group, and then after several iterations, the number of decision makers in the acceptable group attains the predesigned threshold.

\section{Conclusion}

The proposed derivation provides a patch work for incompleteness in Macharis et al. [2]. A structured and transparent algorithm was developed to help researchers apply the consistent comparison matrix for AHP proposed by the previous study. Further investigations allowed this study to point out two new criteria for the selection of changing entries to avoid an endless revision process. These findings permit researchers to gain a deeper insight into the consistent comparison matrix problem in AHP.

\section{Data Availability}

The data used to support the findings of this study are available from the corresponding author upon request.

\section{Conflicts of Interest}

The authors declare that they have no conflicts of interest.

\section{Acknowledgments}

This research is partially supported by Ministry of Science and Technology, R.O.C. (Taiwan), with Grant no. MOST 1062410-H-156-009.

\section{References}

[1] C.-Y. Baek, K.-H. Park, K. Tahara, and Y.-Y. Chun, "Data quality assessment of the uncertainty analysis applied to the greenhouse gas emissions of a dairy cow system," Sustainability, vol. 9, no. 10, 2017.

[2] C. Macharis, J. Springael, K. De Brucker, and A. Verbeke, "PROMETHEE and AHP: the design of operational synergies in multicriteria analysis. Strengthening PROMETHEE with ideas of AHP," European Journal of Operational Research, vol. 153, no. 2, pp. 307-317, 2004.

[3] Y. Dong and E. Herrera-Viedma, "Consistency-Driven Automatic Methodology to Set Interval Numerical Scales of 2-Tuple Linguistic Term Sets and Its Use in the Linguistic GDM with Preference Relation," IEEE Transactions on Cybernetics, vol. 45, no. 4, pp. 780-792, 2015.

[4] Y. Dong, H. Zhang, and E. Herrera-Viedma, "Consensus reaching model in the complex and dynamic MAGDM problem," Knowledge-Based Systems, vol. 106, pp. 206-219, 2016.
[5] C.-C. Li, R. M. Rodríguez, L. Martínez, Y. Dong, and F. Herrera, "Personalized individual semantics based on consistency in hesitant linguistic group decision making with comparative linguistic expressions," Knowledge-Based Systems, vol. 145, pp. 1-14, 2018.

[6] S. Alonso, F. Chiclana, F. Herrera, E. Herrera-Viedma, J. AlcaláFdez, and C. Porcel, "A consistency-based procedure to estimate missing pairwise preference values," International Journal of Intelligent Systems, vol. 23, no. 2, pp. 155-175, 2008.

[7] H. E. Mutikanga, S. K. Sharma, and K. Vairavamoorthy, "Multicriteria Decision Analysis: A Strategic Planning Tool for Water Loss Management," Water Resources Management, vol. 25, no. 14, pp. 3947-3969, 2011.

[8] F. Salardini, "An AHP-GRA method for asset allocation: A case study of investment firms on Tehran Stock Exchange," Decision Science Letters, vol. 2, no. 4, pp. 275-280, 2013.

[9] S. M. Hashemian, M. Behzadian, R. Samizadeh, and J. Ignatius, "A fuzzy hybrid group decision support system approach for the supplier evaluation process," The International Journal of Advanced Manufacturing Technology, vol. 73, no. 5-8, pp. 11051117, 2014.

[10] R. Parajuli, M. T. Knudsen, and T. Dalgaard, "Multi-criteria assessment of yellow, green, and woody biomasses: Prescreening of potential biomasses as feedstocks for biorefineries," Biofuels, Bioproducts and Biorefining, vol. 9, no. 5, pp. 545-566, 2015.

[11] M. A. Rahman, L. Jaumann, N. Lerche et al., "Selection of the Best Inland Waterway Structure: A Multicriteria Decision Analysis Approach," Water Resources Management, vol. 29, no. 8, pp. 2733-2749, 2015.

[12] G. A. Ayoko, L. Morawska, S. Kokot, and D. Gilbert, "Application of Multicriteria Decision Making Methods to Air Quality in the Microenvironments of Residential Houses in Brisbane, Australia," Environmental Science \& Technology, vol. 38, no. 9, pp. 2609-2616, 2004.

[13] A. Soltani and E. Z. Marandi, "Hospital site selection using twostage fuzzy multi-criteria decision making process," Journal of Urban and Environmental Engineering, vol. 5, no. 1, pp. 32-43, 2011.

[14] E. Wang, Z. Shen, J. Neal, J. Shi, C. Berryman, and A. Schwer, "An AHP-weighted Aggregated data quality indicator (AWADQI) approach for estimating embodied energy of building materials," The International Journal of Life Cycle Assessment, vol. 17, no. 6, pp. 764-773, 2012.

[15] D. D. Alexakis and A. Sarris, "Integrated GIS and remote sensing analysis for landfill sitting in Western Crete, Greece," Environmental Earth Sciences, vol. 72, no. 2, pp. 467-482, 2014.

[16] C.-W. Tsui and U.-P. Wen, "A hybrid multiple criteria group decision-making approach for green supplier selection in the TFT-LCD industry," Mathematical Problems in Engineering, vol. 2014, Article ID 709872, 13 pages, 2014.

[17] F. Feizi, A. KarbalaeiRamezanali, and E. Mansouri, "Calcic iron skarn prospectivity mapping based on fuzzy AHP method, a case Study in Varan area, Markazi province, Iran," Geosciences Journal, vol. 21, no. 1, pp. 123-136, 2017.

[18] F. Feizi, A. Karbalaei-Ramezanali, and H. Tusi, "Mineral Potential Mapping Via TOPSIS with Hybrid AHP-Shannon Entropy Weighting of Evidence: A Case Study for Porphyry$\mathrm{Cu}$, Farmahin Area, Markazi Province, Iran," Natural Resources Research, vol. 26, no. 4, pp. 553-570, 2017.

[19] R. U. Bilsel, G. Büyüközkan, and D. Ruan, "A fuzzy preferenceranking model for a quality evaluation of hospital web sites," 
International Journal of Intelligent Systems, vol. 21, no. 11, pp. 1181-1197, 2006.

[20] N. Ramzan, S. Degenkolbe, and W. Witt, "Evaluating and improving environmental performance of HC's recovery system: A case study of distillation unit," Chemical Engineering Journal, vol. 140, no. 1-3, pp. 201-213, 2008.

[21] M. E. Fontana and D. C. Morais, "Using PROMETHEE V to select alternatives so as to rehabilitate water supply network with detected leaks," Water Resources Management, vol. 27, no. 11, pp. 4021-4037, 2013.

[22] M. S. Roodposhti, S. Rahimi, and M. J. Beglou, "PROMETHEE II and fuzzy AHP: An enhanced GIS-based landslide susceptibility mapping," Natural Hazards, vol. 73, no. 1, pp. 77-95, 2014.

[23] N. Pourghahreman and A. Rajabzadeh Qhatari, "Supplier selection in an agent based pharmaceutical supply chain: An application of TOPSIS and PROMETHEE II," Uncertain Supply Chain Management, vol. 3, no. 3, pp. 231-240, 2015.

[24] Z. Andreopoulou, C. Koliouska, C. Lemonakis, and C. Zopounidis, "National Forest Parks development through Internet technologies for economic perspectives," Operational Research, vol. 15, no. 3, pp. 395-421, 2015.

[25] N. Vesyropoulos and C. K. Georgiadis, "QoS-Based Filters in Web Service Compositions: Utilizing Multi-Criteria Decision Analysis Methods," Journal of Multi-Criteria Decision Analysis, vol. 22, no. 5-6, pp. 279-292, 2015.

[26] G. X. Wang, S. H. Huang, Y. Yan, and J. J. Du, "Reconfiguration schemes evaluation based on preference ranking of key characteristics of reconfigurable manufacturing systems," The International Journal of Advanced Manufacturing Technology, vol. 89, no. 5-8, pp. 2231-2249, 2017.

[27] R. A. R. Ghazilla, Z. Taha, S. Yusoff, S. H. A. Rashid, and N. Sakundarini, "Development of decision support system for fastener selection in product recovery oriented design," The International Journal of Advanced Manufacturing Technology, vol. 70, no. 5-8, pp. 1403-1413, 2014.

[28] M. Hamzeh, R. Ali Abbaspour, and R. Davalou, "Raster-based outranking method: a new approach for municipal solid waste landfill (MSW) siting," Environmental Science and Pollution Research, vol. 22, no. 16, pp. 12511-12524, 2015.

[29] S. Vinodh, T. S. Sai Balagi, and A. Patil, "A hybrid MCDM approach for agile concept selection using fuzzy DEMATEL, fuzzy ANP and fuzzy TOPSIS," The International Journal of Advanced Manufacturing Technology, vol. 83, no. 9-12, pp. 19791987, 2016.

[30] L. Zhang, J. Yu, B. K. Sovacool, and J. Ren, "Measuring energy security performance within China: Toward an inter-provincial prospective," Energy, vol. 125, pp. 825-836, 2017.

[31] T. L. Saaty, "Axiomatic foundation of the analytic hierarchy process," Management Science, vol. 32, no. 7, pp. 841-855, 1986.

[32] T. L. Saaty, The Analytic Hierarchy Process, McGraw-Hill, NY, USA, 1980.

[33] Y. Dong, S. Zhao, H. Zhang, F. Chiclana, and E. HerreraViedma, "A self-management mechanism for non-cooperative behaviors in large-scale group consensus reaching processes," IEEE Transactions on Fuzzy Systems, 2018.

[34] C. Li, R. M. Rodriguez, L. Martinez, Y. Dong, and F. Herrera, "Consensus building with individual consistency control in group decision making," IEEE Transactions on Fuzzy Systems, 2018.

[35] C. Li, Y. Dong, and F. Herrera, "A consensus model for large-scale linguistic group decision making with a feedback recommendation based on clustered personalized individual semantics and opposing consensus groups," IEEE Transactions on Fuzzy Systems, 2018. 


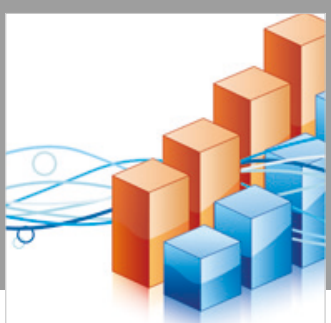

Advances in

Operations Research

\section{-n-m}
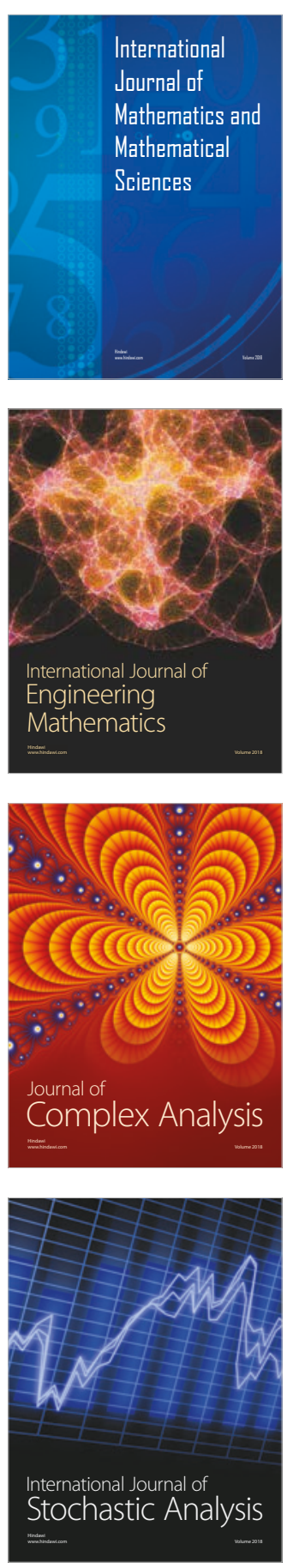
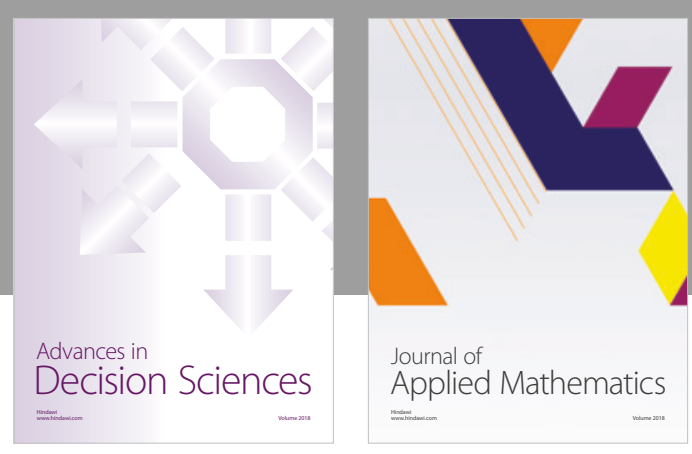

Journal of

Applied Mathematics
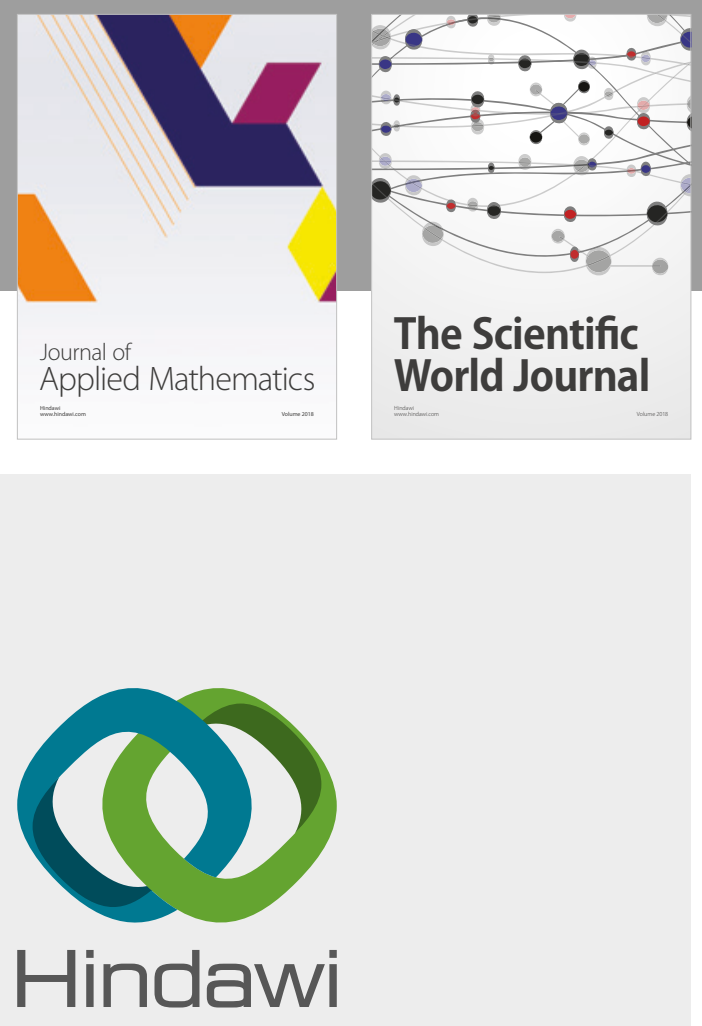

Submit your manuscripts at

www.hindawi.com

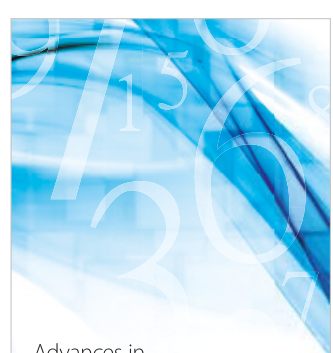

Advances in
Numerical Analysis
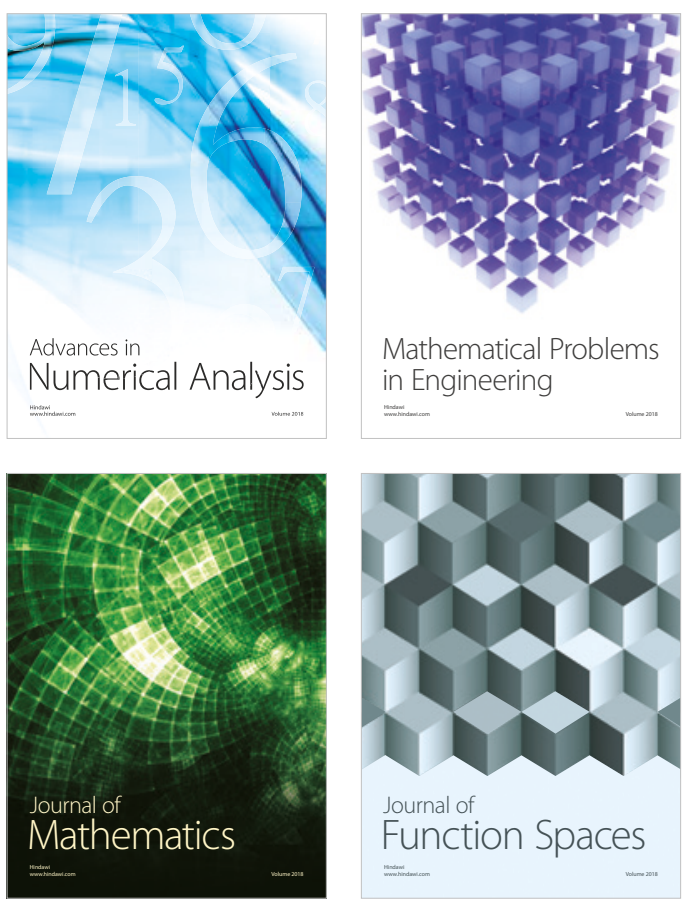

Mathematical Problems in Engineering

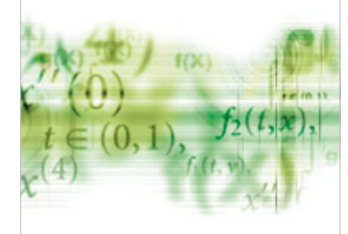

International Journal of

Differential Equations

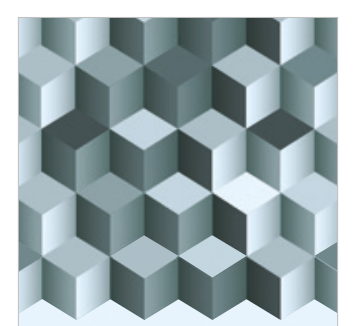

Journal of

Function Spaces

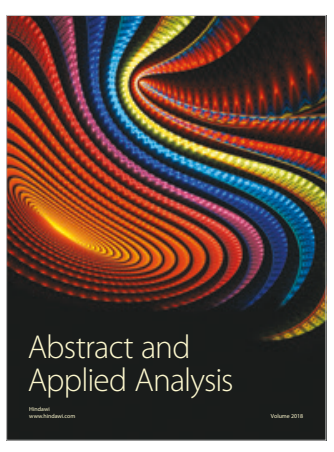

The Scientific

World Journal

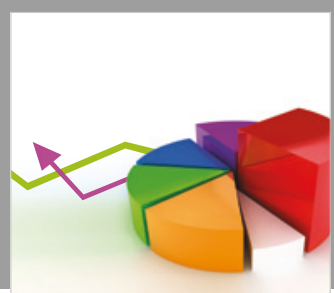

Journal of

Probability and Statistics
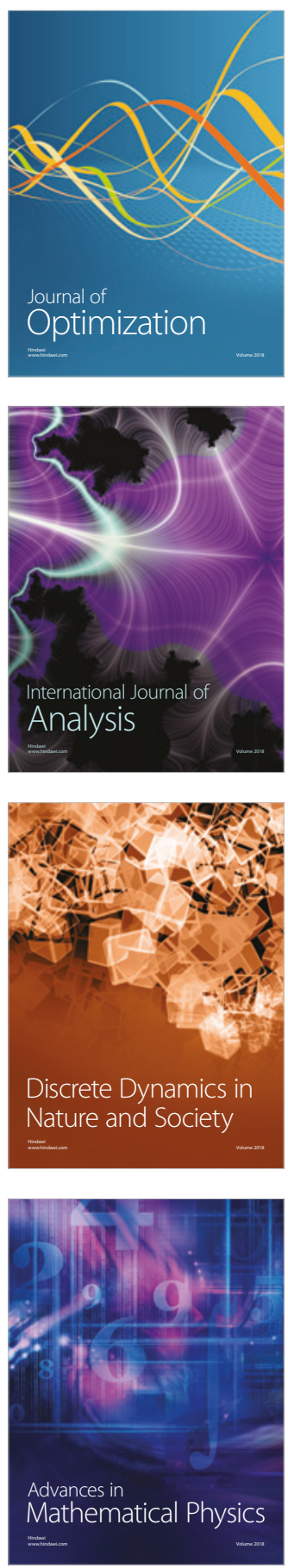